\title{
The Influence of Indonesian National and Military Organisational Culture on Safety Management Systems
}

\author{
Medi Rachman*, Bernard Mees, Simon Fry \\ RMIT University, 445 Swanston Street, VIC 3000, Australia \\ *Tel: +61 451201499 \\ *Email: medi.rachman@rmit.edu.au
}

doi:10.5296/jss.v2i2.10445 URL: http://dx.doi.org/10.5296/jss.v2i2.10445

\begin{abstract}
This paper examines the influence of Indonesian national and military organisational culture on the adoption and implementation of the Safety Management System (SMS) that is predominantly based on Western concepts of management. The influence of national culture on a military organisational culture, the perception and behaviour of the military members, and how management handles safety issues in the organisation were investigated and identified. To discover and understand the basic assumptions of a culture that drive people to a particular behaviour, a qualitative research design, encompassing multiple case studies, was adopted for this study. Analysis of the findings shows that the Indonesian military culture has been much influenced by its national culture. Moreover, the unique characteristics of the Indonesian national and military culture have significant influences on military SMS. Harmony, politeness, hierarchical systems, authoritarian structures, the military class system and the 'can-do' culture are some of the cultural factors that impede the promotion of safety culture as well as the implementation of the SMS within the Indonesian military organisation. In addition to those cultural factors, the lack of safety education and training has created an environment in which individual safety awareness is disregarded. The results of this study demonstrate that cultural factors are one of the crucial factors that must be integrated into the organisation's system in order to achieve safety.
\end{abstract}

Keywords: safety, safety culture, SMS, military safety 


\section{Introduction}

Safety is considered as one of the means of maintaining operational readiness and as a method of controlling cost (Wood, 1997). Thus, safety for any military aviation organisation is one of the crucial factors that must be integrated into the system and cannot be compromised. Incidents or accidents that occur in any military organisation bring losses of some of its valuable assets and degradation of its military capability. Consequently, incidents or accidents will significantly affect its operational readiness. Moreover, aviation accidents hurt morale and may cost the lives of military personnel (DoD, 2006). Therefore, safety and continuing efforts to prevent accidents are major priorities.

Military organisations have been employing various safety measures to prevent mishaps and improve safety. In addition to the improvements in aircraft technology, improved pilot training, enhanced navigation aids, better regulations and weather forecasting, and careful and thorough aircraft accident investigations are some methods used to improve safety (Oster, Strong, \& Zorn, 2013), military organisations have also introduced and implemented a Safety Management System (SMS). An SMS is a management system that can be used to improve an organisation's ability to construct, understand and manage safety systems proactively (Stolzer, Halford, \& Goglia, 2008). Since the introduction and implementation of SMS in early 2000 in the aviation industry, it is acknowledged that the SMS is one of the important factors that contribute to further reductions in aircraft incidents and accidents (Flouris \& Kucukyilmaz, 2009). However, an SMS cannot be implemented efficiently and effectively if an organisation does not possess a healthy safety culture (Hopkins, 2005; ICAO, 2013).

Quantitative research is the most commonly applied technique in safety culture research; relatively little research using qualitative techniques has been conducted. Quantitative and qualitative approaches have their respective advantages and disadvantages. It is argued here that a quantitative approach to safety climate will narrowly provide a snapshot of organisational safety culture (Mearns, Whitaker, \& Flin, 2003; Wiegmann, Zhang, Von Thaden, Sharma, \& Gibbons, 2004) and cannot uncover the basic assumptions or beliefs of the culture itself (Mearns \& Flin, 1999; Antonsen, 2009). Similarly, little is known about how the basic assumptions or beliefs that drive people to particular behaviour within an organisation can influence safety (Patankar, Brown, Sabin, \& Bigda-Peyton, 2012). Moreover, the impacts of national and military culture on safety have not been addressed in the small amount of safety climate research which has been conducted in military organisations to date.

This paper examines the influence of Indonesian national culture and military organisational culture on SMS. This paper also reveals that Indonesian culture was used as an initial assessment to measure the effectiveness of the SMS implementation in Indonesian military organisations. Although the Indonesian military organisation has adopted and implemented the aviation SMS, which is predominantly based on the Western conceptions of management (Guldenmund, 2000), the organisation still experiences a considerable number of aircraft accidents. Based on the author's data set compiled from a number of confidential publications and official documents, more than ten aircraft accidents occurred and hundreds of people have died as a result of those mishaps in the last five years. The fact that aircraft accidents still occur demonstrates that the introduction and implementation of the new SMS are not adequate to prevent mishaps. The facts also show that there might be an influential factor that significantly obstructs the implementation of the SMS and has not yet been sufficiently addressed. Since safety of defence systems is subject to safety culture (Reason, 1997) and safety culture is influenced by cultural factors (Helmreich \& Merritt, 1998), the aim of this 
study is to disclose and provide answers to a research question: "How do Indonesian national and military cultures influence Safety Management Systems?”. Following the introduction, this paper is structured as follows: Section 2 presents a review of the literature on culture, safety culture and safety climate, and the relationship between SMS and safety culture; Section 3 describes the research method; findings and discussion, and conclusion are provided in Sections 4 and 5 respectively.

\section{Literature Review}

\subsection{Culture}

Various definitions of the term 'culture' can be found in the scientific literature. The various definitions of culture have emerged as a result of several factors such as the academic discipline from where they originate (Flouris \& Kucukyilmaz, 2009; Sewell, 2005) and the different usages of the word (Sewell, 2005; Avruch, 1998). Spencer-Oatey (2012) believes that the debate regarding culture is not merely conceptual or semantic, but also includes all of the usages and understandings to which it has become attached, or that can be attached to it, as well as different political or ideological agendas. However, it is commonly accepted that culture is continually being generated and established by people's interactions with others (Kluckhohn, 1941; Schein, 2004; Trompenaars \& Hampden-Turner, 1997); culture emerges from processes of people coping with uncertainties and the results of the process become, to some degree, a guidance or order in social life (Trice \& Beyer, 1993); and culture is institutionalized in a society or group and difficult to change (Kluckhohn, 1949; Guldenmund, 2010).

Each society has its own cultural values which are the fundamental norms that guide people in doing what is appropriate in various situations (Schwartz, 2006). Vallues are defined as "conceptions of the desirable that guide the way social actors (e.g. organisational leaders, policy-makers, individual persons) select actions, evaluate people and events, and explain their actions and evaluations. Values are trans-situational criteria or goals, ordered by importance as guiding principles in life" (Schwartz, 1999, p. 24). The cultural values orientation can be used to identify dimensions that are used to differentiate one culture from another (for examples of the proposed cultural value dimensions see Hofstede, 1991; Trompenaars \& Hampden-Turner, 1997; House, Hanges, Javidan, Dorfman, \& Gupta, 2004; Schwartz, 2006). Although, there has been much debate about clustering culture at a national level as this simplifies the complexities of culture (Bakerville, 2003; Baskerville-Moley, 2005; Woodside, Hsu, \& Marshall, 2011), findings of the studies have revealed that there is a similarity between cultural value orientations within countries. Havold (2007) believes that the values and beliefs underpinning national cultures influence individual behaviour through the values and beliefs they form about what type of behaviour is legitimate, acceptable and effective.

In the field of aviation safety, the importance of national culture has been discussed in a few research papers (e.g. Sherman, Helmreich, \& Merritt, 1997; Helmreich \& Merritt, 1998; Merritt, 2000; Soeters \& Boer, 2000). The results of the research show that personnel's attitudes and values, to some extent, have been influenced by their respective national cultures. Nevertheless, Helmreich and Merritt (1998) argue that there are several inconclusive findings with large-scale studies. For instance, the motivations underlying behaviours and the true uniqueness of national culture cannot be captured by these studies. Furthermore, Helmreich and Merritt (1998) contend that there is no one national culture that is superior to 
another, and that every national culture has its weakness and strength in terms of influencing aviation safety.

Indonesia has its own cultural values orientation and approaches when dealing with day-today problems. Even though Indonesia consists of many tribes, ethnic groups, religions and languages, there are several prominent characteristics of Indonesian culture that are accepted and practised by the society in general. Runyan (1998), Koentjaraningrat (1988), Irawanto, Ramsey, \& Ryan (2011), and Woodward (2011) claim that the Indonesian culture has been greatly influenced by Javanese culture since the Javanese are culturally and politically dominant in Indonesia. Hess (2001) asserts that the influence of attitudes rooted in traditional Javanese practices appears to determine the work attitude in Indonesia, especially in the public sector. Some of the prominent characteristics of the Indonesian national culture include respect for social hierarchy, valuing communal harmony in higher esteem than individual rights (Runyan, 1998), collectivism (Rajiani \& Jumbri, 2011), harmony in life (Irawanto et al., 2011), respect to elder people, and be humble and polite while demonstrating correct behaviour (Geertz, 1960). It is inappropriate and impolite to directly refuse or confront elders or superiors.

According to Trice and Beyer (1993), national culture is one of the factors that influence the substance of an organisation culture that is an organisation's ideologies. Other factors that have a significant influence on the organisation ideologies include transnational cultures, regional and community cultures, industry culture, occupational culture, and other organisations' cultures (Trice \& Beyer, 1993). A military organisation, like any other organisation, has its own distinctive culture which is shaped and influenced by several factors such as the unique requirements of its workplace, the resources devoted to national defence, the way the military is organised and conducts its missions, its history and geography, the professional ethos, recent military experience, and the environment within which the organisation operates (Hillen, 1999; Murray, 1999). The main characteristics of military culture are discipline, professional ethos, the ceremonies and etiquette, cohesion and esprit de corps, authoritarian structure, class system, the importance of the mission, and preparation for disaster (Burk, 1999; Hall, 2011).

\subsection{Safety Culture and Safety Climate}

The term 'safety culture' first officially emerged in the report of the nuclear accident at Chernobyl in 1986 (Cox \& Flin, 1998; Mearns \& Flin, 1999; Braithwaite, 2011; Antonsen, 2012). Similar to the term 'culture', there is no universally accepted definition of the concept of safety culture even though it has attracted much research (Reason, 1998; Hopkins, 2006; Antonsen, 2009). These uncertainties are reflected in the articles written by Cox \& Flin (1998), Hale (2000), and Zhang, Wiegmann, von Thaden, Sharma, \& Mitchell (2002). The unresolved definition of culture and the concept of safety culture have made Hale (2000), Hopkins (2006) and Antonsen (2009) contend that there is no such thing as safety culture, but there is a cultural impact on organisational safety. Nonetheless, for the purpose of this paper and simplicity, the term 'safety culture' will be used. Based on a literature review, Guldenmund (2000) concludes that a set of shared attitudes, values and assumptions among the members of an organisation is what makes the concept of safety culture valid.

Some scholars believe that safety culture is synonymous with safety climate. However, safety culture is different from safety climate as climate is a manifestation of culture (Mearns et al., 2003), and culture is not measurable and abstract, while climate is directly measurable 
(Mearns et al., 2003). Culture also refers to phenomena that last for a long time, whereas climate refers to a situation at a particular point in time (Hale, 2000). Moreover, culture refers to behaviour, and climate refers to attitudes (Guldenmund, 2000). Zhang et al. (2002, p. 3) define safety culture as:

"The enduring value and priority placed on worker and public safety by everyone in every group at every level of an organisation. It refers to the extent to which individuals and groups will commit to personal responsibility for safety; act to preserve, enhance and communicate safety concerns; strive to actively learn, adapt and modify (both individual and organizational) behaviour based on lessons learned from mistake; and be rewarded in a manner consistent with these values";

while a safety climate is defined as:

"The temporal state measure of safety culture, subject to commonalities among individual perceptions of the organisation. It is therefore situationally based, refers to the perceived state of safety at a particular place at a particular time, is relatively unstable, and subject to change depending on the features of the current environment or prevailing conditions."

According to Reason (1997), a safety culture has five sub-components: a reporting culture in which people voluntarily report any safety-related concern; a just culture in which essential safety-related information is equally distributed within the organization; a flexible culture in which people can flexibly alter the working condition from the conventional hierarchical mode to a flatter mode with respect to safety; a learning culture in which any safety-related information is thoroughly examined, and if required, people make changes accordingly. The interactions of these four subcomponents of safety culture will generate an informed culture where people possess safety knowledge, and are aware that the environmental, organisational, technical and human factors are closely linked to create a good safety system (Reason, 1997).

\subsection{SMS and Safety Culture}

An SMS can be a powerful framework that provides guidance for organisations regarding safety philosophy, methodologies and tools, which can be used to enhance organisations' ability to comprehend, develop and manage safety systems proactively (Stolzer et al., 2008). Based on many research findings, the success of SMS implementation depends upon two factors: management commitment and supervisory support that can create a safety culture within the organization (Blair, 2013). Organisations require a good safety culture as this affects safety performance of an organisation and can be a predictor of it (Blair, 2013; Booth \& Lee, 1995). Eurocontrol (2008) contends that SMS and safety culture are two interdependent entities: an SMS indicates the organisation's ability to achieve safety, while safety culture refers to the commitment to achieve safety. Therefore, since safety culture is greatly influenced by cultural factors (Helmreich \& Merritt, 1998), the implementation of the SMS will also be affected by cultural factors.

\section{Methods}

This study utilised a qualitative approach and encompassed case studies to investigate the influence of Indonesian national and military culture on SMS. Case studies offer a research approach that allows researchers to examine a contemporary phenomenon within its natural context in order to acquire a deep understanding of the actors, behaviours, sentiments and interactions (Woodside, 2010; Hancock \& Algozzine, 2006; Yin, 2009). 
The multiple case studies involved two air operational units. This study has considered several criteria for the cases that include: the sample units comprise various units that operate different types of aircraft; the sample units have a continuous safety program in place and implemented the Safety Management System (SMS); the sample units' members have various qualifications such as air crew (pilot, navigator, and engineer), ground crew (maintainer, ground support) and flying support division. Purposive sampling was used in this study and after random and thorough selections of participants, thirteen personnel from two different military units were selected to participate. Participants came from various backgrounds, and comprised eight officers (pilots and technicians) and five enlisted or Non-Commissioned Officers (NCOs) (flight engineers, technicians, and radio operator). Furthermore, participants had been in the service for an average of ten years; the youngest officer has been in the service for seven years and the most senior officer has been in the service for more than twenty years.

Semi-structured interviews, observations and unstructured interviews, and an analysis of written documents and unstructured interviews were the primary techniques used for gathering data. The data collection was conducted concurrently during fieldwork. In each unit, the fieldwork was conducted for five consecutive working days in an environment that was as natural as possible. The natural setting enabled the researcher to have an informal social interaction with the units' members, and observe events that occurred within a certain period of time and place such as meeting and working activities. In the context of observation, the researcher acted as a full observer and observed the participants from a distance. Nonetheless, any ambiguity during observation could still be clarified by the participants during the unstructured interviews.

With respect to written documents, the data were gathered by examining the unit's annual report, unit's safety reports, safety manuals and other related documents. Any ambiguity discovered during the examination of documents was clarified by the participants through unstructured interviews. Semi-structured, face-to-face interviews were conducted with participants in a designated room at an allocated time when the participants were not on duty. The interviews were conducted and recorded in the participants' native language. Each interview lasted between 25 minutes to one hour and was coded chronologically in order to easily track the data. Subsequently, all interviews were transcribed into Microsoft Word documents and then each transcript was sent to each respective interviewee via email to confirm the accuracy of the transcript. This study used member check and data triangulation techniques to validate the data.

Reviewing, coding, categorising, synthesising, and interpreting the evidence from the data sources were steps used to conduct an analysis of the data derived from this study. The data analysis has produced themes related to study propositions that assist the researcher to examine cases. Subsequently, thematic analysis was utilised to recognise patterns within the data. The names of all participants are represented as codes in this paper in order to protect their identities.

\section{Findings and Discussion}

Based on the analysis of the data collected from two cases, several strong themes were revealed: harmony, politeness, hierarchical systems, authoritarian structures, military class system, and can-do culture. 


\subsection{Harmony}

One characteristic of the Indonesian national culture that is revealed in its military organisation is rukun or harmony. Harmony means that people are required to be respectful to others and avoid conflicts (Irawanto, et al., 2011). This characteristic was revealed during one of the observation periods during which one enlisted man or NCO (Non-Commissioned Officer) of the unit behaved inappropriately by smoking under the no-smoking sign. Other enlisted men in the unit who witnessed this did not intervene and just carried on with their activities. The NCO stopped smoking when an officer approached and asked him to put out his cigarette. One participant, $\mathrm{C} 1$, said that he was reluctant to tell the NCO to put out his cigarette because he did not want to ruin his relationship with him. Another participant, D1, stated, "I knew that his behaviour was inappropriate, and if I had told him to put out his cigarette, it would be good for us. However, if I had done so, it would have created a conflict between us. So, it was better to just ignore him and wait for someone else to tell him".

In the second unit, E2 believed that maintaining a good relationship with co-workers was far more important than giving a rebuke which will then create a conflict. E2 argued, "My concern was that if I tell my co-worker that he made a mistake, it will make him have a misperception about me. Another difficult thing being in the military is if someone who makes a mistake is your senior. If I had told him about his mistake, he would have asked me whether I always did everything right and I should not teach a senior. Thus, it was better for me to keep quiet and try not to make any mistake”. One positive aspect of Indonesian culture - to maintain harmony with others - has been misinterpreted by the member of the units. This incident is indicative of one characteristics of the Indonesian mentality that emerged after independence - apathy (Koentjaraningrat, 1988). It showed that members of the unit lacked interest, enthusiasm, or concern about participating in a project.

\subsection{Politeness}

E1 stated that the culture of unggah-ungguh or politeness has shaped another attitude of the members of the units. E1 explained that this attitude makes subordinates unwilling to report safety issues regarding themselves or their working environment since they were apprehensive about their superiors' perceptions. For instance, a person who was medically unfit for duty would conceal this fact from his superiors. He was afraid that his superiors would think that he was seeking an excuse for not working, which ultimately would affect his work performance assessments. A1 also believed that "If we want to report our concerns, we need to wait until the right moment. We cannot just go to our superior and tell about our problem. We also need to be cautious when explaining our problem because we have to talk in a polite way. If our superior is not in a good mood, there would be a backlash against us, and we would not be able to deliver our messages correctly". Moreover, C2 contended that the politeness culture in his military organisation had established condition in which the subordinates were reluctant to describe the actual condition of the unit. Most of the time, the subordinates would claim that they did not have any serious issues, including safety issues, when conducting their tasks. Subordinates assume that if they report the actual condition of the unit, this would be considered as a sign of disloyalty to superiors and disobedience to any given instruction. Furthermore, the subordinates would conceal any situation that would be unsatisfactory for their superiors, who would then think that everything was working as prescribed. 


\subsection{Hierarchical Systems}

Hierarchical systems have created situations which prevent the personnel in charge of a unit from directly receiving information from their subordinates. Members of units need to follow established rules and procedures if they want to make a report. According to A1, a unit commanding officer, it was difficult to encourage subordinates to report any issue voluntarily as the hierarchical systems, to some extent, had created a complex system of bureaucracy that prevents subordinates from directly conveying messages to their superiors. Moreover, A1 claimed that "The prevailing condition forced me to go to the field more often in order to see the real working conditions of my men. Otherwise, I would not get any factual information in real time. The hierarchical system forced my subordinates to report any problem through a chain of command'. B2 asserted that "I had to go to my direct supervisor if I had any problem most of the time. I was not allowed to report directly to the Commandant as there was a system in place and I needed to obey its rules". One disadvantage of this hierarchical system is that any issue has to be reported through a chain of command and will be filtered by layers of supervisors. Not only will it take more time, but also there is the possibility that a report will not reach, or be altered by the time it reaches, the authority or commandant, for various reasons.

\subsection{Authoritarian Structures}

The authoritarian structure is one the characteristics of both the Indonesian national and military organisation cultures. F1 argued that this characteristic has a critical influence on implementation of a safety program and the promotion of a safety culture. The authoritarian structure requires that all unit members seek approval from the higher command or authority if they want to make any change to the existing regulations or procedures. F1 believed that this situation discouraged subordinates from taking any safety initiatives. Consequently, the subordinates have become passive members of the unit and perform tasks as instructed by their superiors. A2 asserted that "Most of us were reluctant to propose any initiative since most of our superiors rarely consider our feedbacks as they have made their own decisions already. So, it was better for us to just carry out their orders". B2 claims that "Our military culture was in line with Indonesian culture; thus, subordinates had to be loyal to their superiors. Everything had to come from superiors, and if we were against them, we would be marginalised". This authoritarian structure creates an environment that prevents the promotion of a flexible culture, as the working conditions are inflexible, making the transition from a centralised to a decentralised environment close to impossible. Moreover, a proactive culture, which is one of the conditions necessary for the implementation of the SMS (Flouris \& Kucukyilmaz, 2009) cannot eventuate since subordinates are reluctant to report any potential hazards.

\subsection{Military Class System}

A class structure in the military divides the unit members into two categories: officers and non-officers (non-commissioned officers /NCO). In unit 1, there was one positive activity: briefs at the end of each day and week. The briefs are intended to evaluate tasks that have been executed daily and weekly respectively. Unfortunately, all attendees at both briefs were officers, with no NCO representative. At the briefs, there is a discussion of every important issue or piece of information that could affect the execution of the missions. The NCOs, who were the front-liners of the units and could have provided critical information, were not 
present at the briefs. Results of the briefs or meetings are disseminated by assigned officers to the members of the unit.

\subsection{Can-do Culture}

A 'can-do' approach is one of the prominent characteristics of military culture. F2 argued that "As military personnel, the most important thing I needed to say when $\mathbb{I}$ received an order was to say 'YES'. Any issue that potentially hinders our task is another matter. First, we need to get the job done by any means". C1 believed that "Hierarchy in military means that any personnel with lower rank has to be able to carry out order given by his superiors. Getting the job done means that we are showing loyalty and respect to superiors". A1 contended that getting a job done was important as it determined someone's future career. Although members of the units undertake calculated risk assessments before conducting jobs, the cando culture disregards the risk associated with the task as they give higher priority to getting the job done and satisfy their superiors. It is evident that members of units are willing to take greater risks for a variety of reasons.

\subsection{Safety Education and Training}

In addition to those cultural factors, most participants believed that lack of safety training or education has resulted in poor individual safety awareness. At the time of this study, only a few officers had received official safety training or course in their respective units. It was a quite challenge for those officers to provide safety training for all members in their units, given that they had their own daily tasks to accomplish. D1, a unit's safety officer, argued "Being a unit safety officer was a challenge. On the one hand, I was responsible for ensuring that working conditions in this unit were safe. On the other hand, I also had to ensure that I could accomplish my own daily duties on time. It was a very demanding job since individual safety awareness of most of the unit's members was still low". To successfully implement the SMS, Stolzer et al. (2008) argue that the individual has to be trained in standardised SMS. The situation in the unit creates unprecedented challenges for the promotion of a safety culture and implementation of the SMS because members have various levels of education. E2 contended that "Basically, all members of the unit knew that safety was important. However, the members' applications of safety to the field were various. Personnel's various educational backgrounds, culture, and their home environments build different perceptions and practices of safety".

\section{Conclusion}

Since most of the safety research has employed a quantitative approach, it has been unable to discover the basic assumptions or beliefs of the culture itself; therefore, little is known about the impacts of cultural factors on the effective implementation of SMS. Moreover, the small amount of safety climate and research on military organisations has not addressed the influence of national and military organisational culture on SMS. This study elucidated how national and military organisational culture influences safety initiatives.

The results of the study suggest that Indonesian national culture influences the military organisational culture. All participants believe that military organisational culture is in line with its national culture. Moreover, the participants also maintain that the cultural factors have significant influences on aviation safety. 
Based on the data, it is reasonable to conclude that there is a connection between cultural factors and safety practices. Some characteristics of the Indonesian national and military organisational culture have significant influences on the safety culture which consequently affects the implementation of the SMS. The study demonstrates that the cultural factors undermine the unit's effort to create a safe working environment. The results of this study cannot be generalised to other cultures as the different characteristics of a culture will have different impacts on safety practice. More studies are required in order to verify or otherwise that cultural factors do influence the effectiveness of safety programs in other countries and other industries.

\section{Acknowledgment}

The corresponding author wishes to gratefully acknowledge and express appreciation to the Indonesia Endowment Fund for Education (Lembaga Pengelola Dana Pendidikan / LPDP) for providing support and scholarship which allow the corresponding author to undertake doctorate program.

\section{References}

Antonsen, S. (2009). Safety Culture Assessment: A mission Impossible?, Journal of Contingencies and Crisis Management, Vo. 17, No. 4, pp. 242-254.

Antonsen, S. (2012). Safety Culture: Theory, Method, and Improvement, Ashgate Publishing Limited, England.

Avruch, K. (1998). Culture and Conflict Resolution, United States Institute of Peace Press, Washington D.C.

Baskerville, R.F. (2003). Hofstede Never Studied Culture, Accounting, Organisations and Society, 28, pp. 1-14.

Baskerville-Morley, R.F. (2005). A Research Note: the Unfinished Business of Culture, Accounting, Organisations and Society, 30, pp. 389-391.

Blair, H. B. (2013). Building Safety Culture, Professional Safety, 59-65, www.asse.org, viewed 5 March 2014, http://www.asse.org/professionalsafety/pastissues/058/11/F3Blair_1113.pdf

Booth, R.T. \& Lee, T.R. (1995). The role of human factors and safety culture in safety management, Journal of Engineering Manufacture, pp. 393-400.

Braithwaite, G. (2011). Safety Management Systems in Aviation, in O’Connell, J.F. \& Williams, G., Air Transport in the 21st Century, Ashgate Publishing Ltd., Farnham, Surrey, GBR.

Burk, J. (1999). Military Culture, Encyclopedia of Violence, Peace and Conflict, Elsevier Inc., 2008.

Cox, S. \& Flin, R. (1998). Safety Culture: Philosopher's Stone or Man of Straw?, Work and Stress, Vol. 12, No. 3, pp. 189-201.

Department Of Defense (DOD) Aviation Safety Initiatives (2006). Cormmittee On Armed Services House Of Representatives One Hundred Eighth Congress Second Session Hearing Held February 11, 2004, U.S. Government Printing Office, Washington. 
Eurocontrol (2008). Safety Culture in Air Traffic Management: A White Paper, Eurocontrol/FAA.

Flouris, T. \& Kucukyilmaz, A. (2009). Change Management as A Road Map for Safety Management System Implementation in Aviation Operations: Focusing on Risk Management and Operational Effectiveness, International Journal of Civil Aviation, vol. 1, no. 1, E1.

Geertz, C. (1960). The Religion of Java, Collier-Macmillan Canada Ltd., Toronto.

Guldenmund, F. (2000). The Nature of Safety Culture: A Review of Theory and Research, Safety Science, 34, pp. 215-257.

Guldenmund, F. W. (2010). (Mis)understanding Safety Culture and Its Relationship to Safety Management, Risk Analysis: An International Journal, Vol. 30, pp. 1466-1480.

Hale, A. (2000). Culture’s Confusions, Safety Science, 34, pp. 1-14.

Hall, L. K. (2011). The Importance of Understanding Military Culture, Social Work in Health Care, Vol. 50, No. 1, pp. 4-18.

Hancock, D.R., \& Algozzine, B. (2006). Doing Case Study Research: A Practical Guide for Beginning Researchers, New York: Teachers College Press.

Havold, J.I. (2007). National Cultures and Safety Orientation: A Study of Seafarers Working for Norwegian Shipping Companies, Work and Stress, Vol. 21, No. 2, pp. 173-195.

Helmreich, R.L. \& Merritt, A.C. (1998). Culture at Work in Aviation and Medicine: National, Organizational, and Professional Influences, Ashgate Publishing Ltd., England.

Hess, M. (2001). Management and Culture under Development, Labour and Management in Development Journal, Vol. 2, No. 3, pp. 2-22.

Hillen, J. (1999). The Future of American Military Culture: Must US Military Reform?, Orbis, pp. 43-57.

Hofstede, G. H. (1991). Cultures and Organizations: Software of the Mind, McGraw-Hill, New York.

Hopkins, A. (2005). Safety, Culture and Risk: The Organizational Causes: of Disasters, CCH Australia Limited.

Hopkins, A. (2006). Studying Organizational Cultures and Their Effects on Safety, Safety Science, 44, pp. 875-889.

House, R. J., Hanges, P.J., Javidan, M., Dorfman, P.W., \& Gupta, V. (2004). Culture, Leadership, and Organisations: The GLOBE Study of 62 Societies, Sage Publications Inc., California.

ICAO (2013). Safety Management Manual (SMM), 3rd Ed., the International Civil Aviation Organization, Montreal, Canada.

Irawanto, D. W., Ramsey, P. L., \& Ryan, J. C. (2011). Tailoring Leadership Theory to Indonesian Culture, Global Business Review, Vol. 12, No. 3, pp. 355-366.

Kluckhohn, C. (1941). The Way of Life, The Kenyon Review, New Series, Vol. 11, No. 1, pp. 143-156.

Kluckhohn, C. (1949). Mirror for Man: the Relation of Anthropology to Modern Life, McGraw-Hill Book Company, Inc., USA.

Koentjaraningrat (1985). Javanese Culture, Oxford University Press, Oxford New York. 
Koentjaraningrat (1988). The Indonesian Mentality and Development, Sojourn: Journal of Social Issues in Southeast Asia, Vol. 3, No. 2, pp. 107-133.

Mearns, K.J. \& Flin, R. (1999). Assessing the State of Organizational Safety - Culture or Climate?, Current Psychology: Developmental, Learning, Personality, Social, Vol. 18, No. 1, pp. 5-17.

Mearns, K., Whitaker, S. \& Flin, R. (2003). Safety Climate, Safety Management Practices and Safety Performance in Offshore Environments, Safety Science, Vol. 41, No. 8, pp. 641680 .

Merritt, A.C. (2000). Culture in the Cockpit: Do Hofstede's Dimension Replicate?, Journal of Cross-Cultural Psychology, Vol. 31, No. 3, pp. 283-301.

Murray, W. (1999). The Future of American Military Culture: Does Military Culture Matter?, Orbis, pp. 27-42.

Oster Jr., C.V., Strong, J.S. \& Zorn, C.K. (2013). Analysing Aviation Safety: Problems, Challenges, Opportunities, Research in Transportation Economics, 43, pp. 148-164.

Patankar, M.S., Brown, J.P., Sabin, E.J., \& Bigda-Peyton, T.G. (2012). Safety Culture: Building and Sustaining a Cultural Change in Aviation and Healthcare, Ashgate Publishing Limited, England.

Rajiani, I. \& Jumbri, I. A. (2011). A Cultural Ecology of New Public Management in Indonesia, Journal of Administrative Science, Vol. 8, Iss. 1, pp. 17-31.

Reason, J. (1997). Managing the Risks of Organizational Accidents, Ashgate Publishing Ltd., England.

Reason, J. (1998). Achieving a Safe Culture: Theory and Practice, Work and Stress, Vol. 12, No. 3, pp. 293-306.

Runyan, C. (1998). Indonesia’s Discontent, World Watch, May/June 1998, pp. 13-23.

Schein, E. H. (2004). Organizational culture and leadership, 3rd Ed. Jossey-Bass., San Francisco, Calif.

Schwartz, S.H. (1999). A Theory of Cultural Value and Some Implications for Work, Applied Psychology: An International Review, Vol. 48. Iss. 1, pp. 23 - 47.

Schwartz, S.H. (2006). A Theory of Cultural Value Orientations: Explication and Applications, Comparative Sociology, Vol. 5. Iss. 2-3, pp. 137 - 182.

Sewell Jr, W. H. (2005). The concept (s) of culture. Practicing history: New directions in historical writing after the linguistic turn, 76-95.

Sherman, P.J., Helmreich, R.L. \& Merritt, A.C. (1997). National Culture and Flight Deck Automation: Results of a Multination Survey, The International Journal of Aviation Psychology, Vol. 7, Iss. 4, pp. 311-329.

Soeters, J.L. \& Boer, P.C. (2000). Culture and Flight Safety in Military Organization, The International Journal of Aviation Psychology, Vol. 10, No. 2, pp. 111-133.

Spencer-Oatey, H. (2012). What is Culture?, Global PAD Core Concept, pp. 1-21.

Stolzer, A.J., Halford, C. D. \& Goglia, J.J. (2008). Safety Management System in Aviation, Ashgate Publishing Limited, Hampshire, England.

Trice, H. M., and Beyer, J. M. (1993). The Cultures of Work Organisations, Prentice Hall, New Jersey. 
Trompenaars, F., \& Hampden-Turner, C. (1997). Riding the Waves of Culture: Understanding Cultural Diversity in Business, Nicholas Brealey Publishing, London.

Wiegmann, D.A., Zhang, H., Von Thaden, T.L., Sharma, G., \& Gibbons, A.M. (2004). Safety Culture: An Integrative Review, the International Journal of Aviation Psychology, Vol. 14, Issue 2, pp. 117-134.

Wood, R.H. (1997). Aviation Safety Programs: A Management Handbook, 2nd Ed., Jeppesen, Colorado, USA.

Woodside, A. (2010). Case Study Research: Theory, Methods and Practice, Emerald Group Publishing Limited.

Woodside, A.G., Hsu, S.Y., \& Marshall, R. (2011). General Theory of Cultures' Consequences on International Tourism Behaviour, Journal of Business Research, 64, pp. 785-799.

Woodward, M. (2011). Java, Indonesia, and Islam, Springer Science+Business Media B.V.

Yin, R.K. (2009). Case Study Research: Design and Methods, 4th Ed., SAGE publication Inc., USA.

Zhang, H., Wiegmann, D.A., von Thaden, T.L., Sharma, G. \& Mitchell, A.A. (2002). Safety Culture: A Concept in Chaos?, Proceeding of the 46th Annual Meeting of the Human Factors and Ergonomics Society, Santa Monica.

\section{Copyright Disclaimer}

Copyright for this article is retained by the author(s), with first publication rights granted to the journal.

This is an open-access article distributed under the terms and conditions of the Creative Commons Attribution license (http://creativecommons.org/licenses/by/3.0/). 